\title{
Properties of Immobilized Papain by Radiation Polymerization
}

\author{
Minoru KUMAKURA and Isao KAETSU \\ Takasaki Radiation Chemistry Research Establishment, \\ Japan Atomic Energy Research Institute, \\ Takasaki, Gunma 370, Japan
}

(Received September 7, 1983)

\begin{abstract}
Papain was immobilized by the radiation polymerization of various monomers at low temperatures and the effects of the polymer matrix on the enzyme activity and thermal stability of the immobilized enzymes were studied. The activity of the immobilized enzymes prepared from monofunctional (acrylate and methacrylate) monomers was higher than that from bifunctional (bismethacrylate) monomers and that from polyoxyethylene dimethacrylate monomers increased with an increase in the number of oxyethylene units. The thermal stability of the immobilized enzymes prepared from hydrophilic monomers was higher than that from hydrophobic monomers and increased markedly with increasing monomer concentration.

KEY WORDS Radiation Polymerization / Immobilized Papain / Thermal Stability / Hydrophilic Monomer / Enzyme Activity /
\end{abstract}

The broad range of uses of immobilized enzymes has prompted investigation of novel enzyme supports, and among them, polymeric materials have been studied for their rather attractive features including the variety of monomers available. Reviews have recently been published on different methods for immobilization of enzymes on various supports. $^{1-4}$ Enzymes are usually stabilized by immobilization. In particular, immobilized proteases are often more stable than native proteases owing to protection from autolysis. The immobilization of proteases, therefore, permits their use in various fields. Properties of immobilized proteases and kinetic studies of the investigation of immobilized proteases have been reported by some workers. ${ }^{5-12}$ However, the relationship between the polymer matrix (support) and inactivation of the enzyme has not been studied in detail.

In this work, papain was immobilized on polymers prepared from various monomers by radiation polymerization and the effects of the polymer matrix on the activity and thermal stability of the immobilized enzymes were studied.

\section{MATERIALS AND METHODS}

\section{Materials}

Papain (from papaya latex, 10 units/mg) was obtained from Sigma Chemical Co. 2Hydroxyethyl methacrylate (HEMA), 2-hydroxyethyl acrylate (HEA), and polyoxyethylene dimethacrylate $\left(\mathrm{CH}_{2}=\mathrm{CCH}_{3} \mathrm{COO}\right.$ $\left.\left(\mathrm{CH}_{2} \mathrm{CH}_{2}\right)_{n} \mathrm{COCCH}_{3}=\mathrm{CH}_{2}, \quad n \mathrm{G}\right)$ were obtained from Shinnakamura Chemical Co., Ltd. Hammarstein casein and trichloroacetic acid were obtained from Merck and Kanto Chemical Co., Ltd., respectively.

\section{Immobilization Procedure}

The enzyme solution, $1.0 \mathrm{ml}$, buffered with $0.1 \mathrm{M}$ phosphate at $\mathrm{pH} 7.4$, containing papain $\left(2.0 \mathrm{mg} \mathrm{ml}^{-1}\right)$, cystein $\left(5 \times 10^{-3} \mathrm{M}\right)$, EDTA $\left(1 \times 10^{-3} \mathrm{M}\right)$, and monomer, was placed in a glass tube $20 \mathrm{~cm}$ in length and $0.8 \mathrm{~cm}$ in diameter. Immediately after shaking, the tube 
was frozen at $-78^{\circ} \mathrm{C}$ and irradiated at an irradiation dose rate of $1.0 \mathrm{MRh}^{-1}$ by $\gamma$-ray from ${ }^{60} \mathrm{Co}$ for $1.0 \mathrm{~h}$. The irradiation temperature was kept at $-78^{\circ} \mathrm{C}$ by immersing the tube in a Dewar flask filled with dry ice-methanol. After irradiation, immobilized enzyme composites obtained by the polymerization were cut into thin pellets $(0.5 \mathrm{~mm}$ in thickness) at room temperature.

\section{Degree of Hydration}

The hydrophilicity of polymers was evaluated by measurement of the degree of hydration, which was determined as the ratio of weight of water to the weight of polymer at swelling equilibrium at $25^{\circ} \mathrm{C}$ in water.

\section{Enzyme Reaction}

Enzyme reaction with the immobilized enzymes was carried out by repeating batch reactions (30 $\mathrm{min}$ ) using $0.5 \%$ Hammarstein casein as a substrate at $25^{\circ} \mathrm{C}$. After reaction, $10 \%$ trichloroacetic acid solution was added to the enzyme reaction solution and the unreacted casein was eliminated by filtration. The absorbance of the filtered solution was mea- sured with a spectrophotometer at $280 \mathrm{~nm}$. The enzyme activity $(\%)$ of the immobilized enzymes of each reaction was relatively determined by hydrolysis of the casein using the immobilized enzymes in comparison with that by an equivalent amount of native enzymes.

\section{Thermal Stability}

The thermal stability of the immobilized enzymes was evaluated by measuring the residual enzyme activity after heat treatment in the buffer solution at various temperatures for $30 \mathrm{~min}$.

\section{RESULTS AND DISCUSSION}

\section{Effects of the Polymer Matrix on Enzyme Activity}

The relationship between the nature of the polymer matrix and activity of the immobilized enzymes was examined. Figure 1 shows the relationship between the enzyme activity and a repeated batch enzyme reaction with immobilized enzymes obtained from various monomers. The enzyme activity was almost constant with increasing repetition of the batch

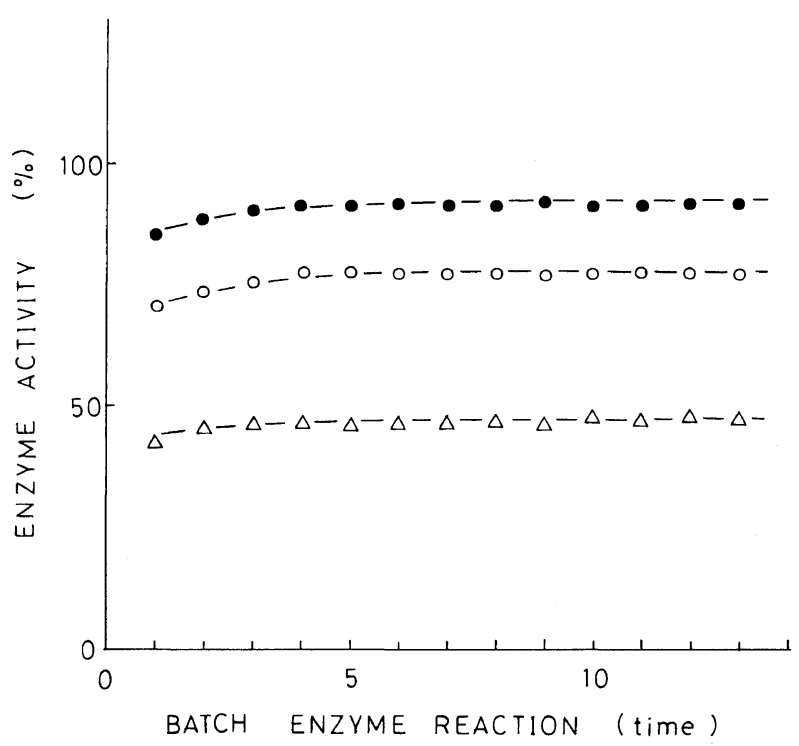

Figure 1. Relationship between enzyme activity and batch enzyme reactions of immobilized papain from various monomers: Monomer: $\mathrm{O}$, HEA; $\mathrm{O}$, HEMA; $\triangle$, 14G. Monomer concentration, $90 \%$. 
enzyme reaction, indicating that the enzymes did not leak from the polymer matrix of the immobilized enzymes. The activity of the enzyme on poly(HEA) was higher than that on poly(14G) and poly(HEMA). Thus, the enzyme activity appeared to depend on the structure of monomers. The degree of hydration of the polymers of HEA, HEMA, and $14 \mathrm{G}$ were $0.45,0.26$, and 0.30 , respectively. The high enzyme activity on poly(HEA) can thus be attributed to the high hydrophilicity of the polymer matrix. Since the principle of the present immobilization is based on the entrapping method, the diffusion of the substrate in the polymer matrix is an important factor for the enzyme reaction. With an increase in the hydrophilicity of the polymer matrix, the rate of the reaction with the immobilized enzymes should be enhanced. The polymer matrix of the immobilized enzymes obtained in this method was relatively rigid because of the high monomer concentration $(90 \%)$, though the polymer matrix swelled in water. Furthermore, the polymer matrix had a porous structure formed by melting of the ice after radiation polymerization at $-78^{\circ} \mathrm{C}$. This porous structure increased the surface area of the immobilized papain. The pore size was affected by monomer concentration and about $0.5 \mu \mathrm{m}$ at a $90 \%$ HEA monomer concentration. ${ }^{13}$ The immobilized enzymes obtained by radiation polymerization of hydrophilic monomers at low temperatures seemed to be trapped on the surface of the polymer matrix, since the enzymes were located between the ice and supercooled monomer phase by freezing of the monomer-enzyme mixture solution in the buffer solution. It is proposed that the trapping of enzymes on the polymer matrix is affected by the nature of monomers. In fact, the enzyme activities on poly(HEA) and poly(HEMA), obtained from monofunctional (acrylate and methacrylate) monomers, were higher than that in poly $(14 \mathrm{G})$ obtained from a bifunctional (bismethacrylate) monomer. The low activity on poly(14G) may be due to the high rigidity of the cross-linked polymer matrix, where the diffusion of the substrate is restricted.

\section{Effects of the Molecular Structure of Mono- mers on the Enzyme Activity}

The enzyme activity of immobilized papain from $n \mathrm{G}$ increased with the increasing number (n) of oxyethylene $\left(\mathrm{CH}_{2} \mathrm{CH}_{2} \mathrm{O}\right)$ units in the monomers (Figure 2). The apparent form of immobilized papain from $n \mathrm{G}$ depended on $n$, and those from the monomers with small $n$ (below $n=4$ ) gave particles and those from the monomers with large $n$ (above $n=9$ ) a bulk form having a porous structure. The monomers with small $n$ were hydrophobic. The formation of immobilized enzyme particles $(100-200 \mu \mathrm{m}$ in diameter) with hydrophobic monomers was a result of radiation polymerization of the suspended monomer solution at low temperatures. The size of the immobilized enzyme particles increased with increasing monomer concentration. Thus, the present immobilization method could produce immobilized enzymes in various forms, according to the type of monomers. The enzyme activity on the polymers with small $n$ was low, as seen in Figure 2, due to a decrease in the amount of the trapped enzymes, even though the enzymes were trapped on the particle surfaces. The low trapping yield of the enzyme in immobilization using hydrophobic monomers thus led to a decrease in relative enzyme activity, owing to the loss of the enzyme during preparation, though there was no restriction of the diffusion of the substrate and product owing to the trapping of the enzyme on the particle surfaces.

\section{Relationship between the Trapping State of the Enzyme and Thermal Stability}

The thermal stability of immobilized papain was found to depend on the nature and concentration of monomers (Figure 3). The thermal stability of immobilized papain was higher than that of native papain, and the 


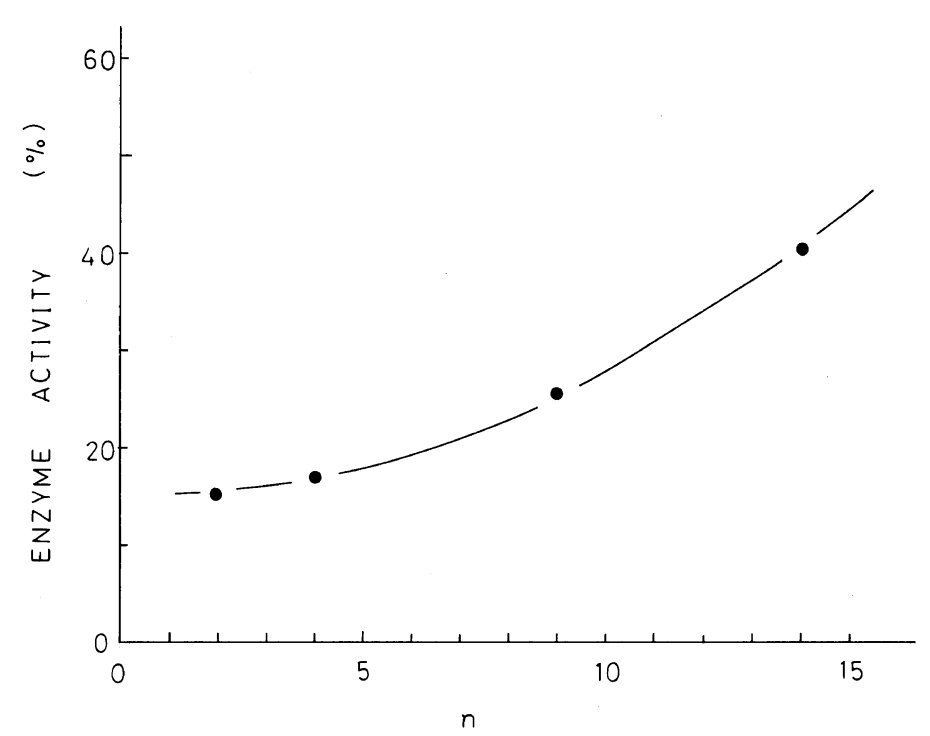

Figure 2. Relationship between enzyme activity and the number $(n)$ of oxyethylene units in $n \mathrm{G}$ monomers: Monomer concentration, $50 \%$.

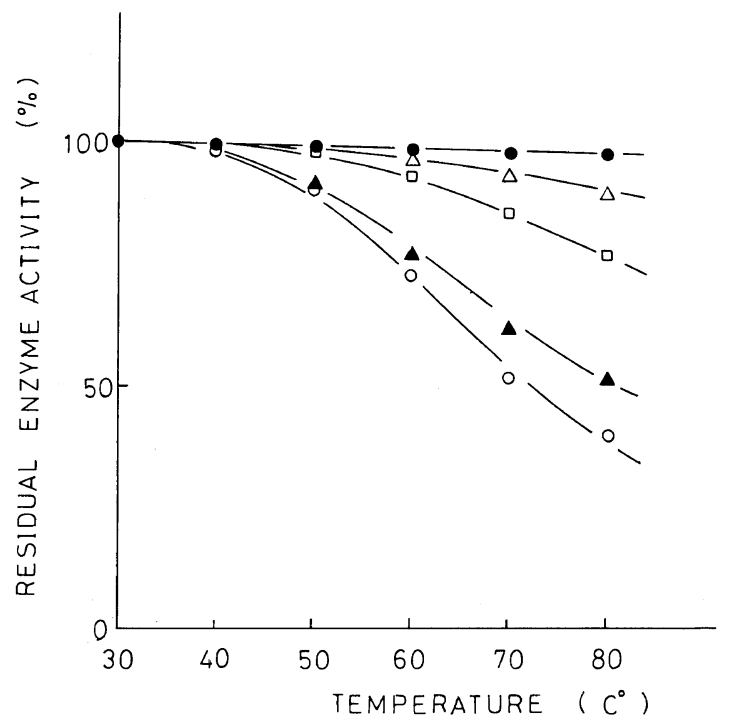

Figure 3. Relationship between residual enzyme activity and heat treatment temperature at $\mathrm{pH}$ 7.4: $90 \%$ HEA; $\triangle, 70 \%$ HEA; $\square, 50 \%$ HEA; $\Delta, 50 \%$ A-2G; 0 , native enzyme.

thermal stability on the polymers from hydrophilic monomers such as HEA was higher than that from hydrophobic monomers with small $n$ (A-2G). This difference in thermal stability is attributed to the difference in the trapping state of the enzyme.
The immobilized enzymes in bulk forms prepared from hydrophilic monomers are considered to be firmly trapped in the porous polymer matrix which protects the enzymes by a soft gel-like matrix, from autolysis and excess thermal motion of the enzyme molecules. 


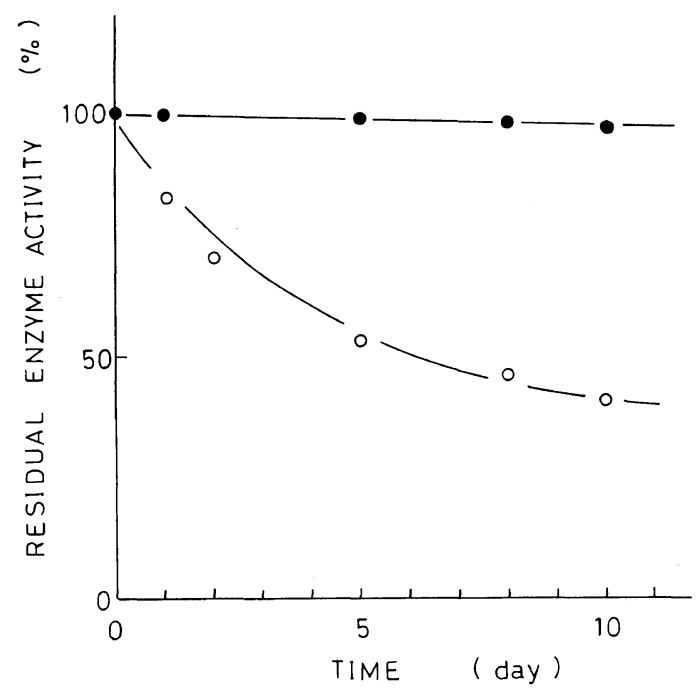

Figure 4. Relationship between residual enzyme activity and heat treatment time at $50^{\circ} \mathrm{C}$ and $\mathrm{pH} 7.4$ : $90 \%$ HEA; $\bigcirc$, native enzyme.

The immobilized enzymes in particle forms prepared from hydrophobic monomers are trapped on the particle surfaces so that the enzymes are attacked by other trapped enzymes, causing the particles to interact with each other. Thus, the enzymes trapped on the particles were affected by autolysis and excess thermal motion. Actually, the thermal stability on A- $n \mathrm{G}$ was comparable with or slightly higher than that of native papain as shown in Figure 3. It was found that the thermal stability in bulk forms prepared from HEA was markedly affected by monomer concentration and that the enzyme activity on the polymer from a $90 \%$ HEA concentration did not decrease by heat treatment even at $80^{\circ} \mathrm{C}$ for 30 min. With an increase in HEA concentration the porous structure of the polymer matrix decreases owing to the decrease in pore size, causing the enzymes to become trapped more firmly on the polymer matrix. This in turn led to an increase in the thermal stability of immobilized papain prepared from high concentrations of hydrophilic monomers. The activity of immobilized papain prepared from a $90 \%$ HEA concentration was stable for a long period of treatment at $50^{\circ} \mathrm{C}$ though that of native papain decreased with an increase in treatment time, as shown in Figure 4.

From these results, it was concluded that the activity and thermal stability of immobilized papain were affected by the nature of polymer matrices and their form and porosity. The immobilized papain obtained by radiation polymerization of hydrophilic monofunctional monomers is excellent from the standpoint of enzyme activity and thermal stability.

\section{REFERENCES}

1. M. Lynn, Enzymology, 1, 1 (1975).

2. O. Zaborsky, "Immobilized Enzymes," CRC Press, Cleveland, Oh, 1974.

3. H. H. Weetall, "Immobilized Biochemicals and Affinity Chromatography," R. B. Dunlap, Ed., Plenum, New York, 1974.

4. B. P. Sharma, L. F. Bailey, and R. A. Messing, Angew. Chem. Int. Ed., 21, 837 (1982).

5. R. Axen and J. Porath, Nature, 210, 367 (1966).

6. D. Gabel and B. V. Hofsten, Eur. J. Biochem., 15, 410 (1970).

7. R. Axen and S. Ernback, Eur. J. Biochem., 18, 351 (1971).

8. L. Ae. Sluyterman and J. Wijdenes, Biotechnol. Bioeng., 23, 1977 (1981).

9. R. Puvamakrishan and S. M. Bose, Biotechnol. Bioeng., 22, 919 (1980).

10. H.-L. Wu and G. E. Means, Biotechnol. Bioeng., 23, 855 (1981).

11. A. M. Klibanov, Anal. Biochem., 93, 1 (1979).

12. A.-C. Koch-Schmidt and K. Mosbach, Biochemistry, 16, 2105 (1977).

13. M. Kumakura and I. Kaetsu, Makromol. Chem., 184, 1831 (1983). 